\title{
Integrating Engineering Design, Analysis and Manufacturing at Sophomore Level
}

\author{
Massoud Tavakoli, Gary Hammond, \\ Jawaharlal Mariappan, Henry Kowalski \\ GMI Engineering \& Management Institute
}

\begin{abstract}
This paper describes the innovations implemented in a traditional sophomore-level introductory design course at GMI over the last three years. The evolution of the ideas, the philosophy behind the innovations and the effects of the changes are discussed. Particular attention is paid to the integration of engineering design, manufacturing and analysis in an introductory course. Also, a series of constraints which are developed to induce more realism into the pedagogical environment are described. Finally, quality control, time and budgetary issues are addressed.
\end{abstract}

\section{INTRODUCTION}

For more than 20 years, the Mechanical Engineering sophomores at GMI have been taking a course entitled "Introduction to Design." The main objectives of this course have always been to learn the design process and apply it to a realistic design project where a device is designed, manufactured and entered into a competition. This is a 3-credit course (1 hour of lecture and two two-hour labs) offered every term, which consists of 11 weeks of instruction and one week of finals.

For the past three years, we have been scrutinizing the effectiveness of this approach in teaching/learning engineering design. We have also studied design processes practiced at several companies, learning from their good and bad design practices. As a result, without deviating from the original intentions of this course, we have significantly modified it based on what we recognized as obstacles to effective learning of the design process.

After nearly three years of implementation, improvement, and student feedback, we now believe that we have an effective approach for learning design. We also have learned that teaching design is an ever-changing process which demands continuous re-design.

\section{TEACHING PHILOSOPHY}

If one accepts the premise that teaching is an art, then it could be said that teaching design is one of the most abstract forms of this art. This statement basically implies that every teacher of design brings his/her own unique design philosophy to the class. Perhaps that is why there are so many different practices of teaching design among the engineering curricula. 
In the past three years, we have recognized the need for a common philosophy in teaching design, especially at the introductory level. Therefore, we developed a 10-point basic teaching philosophy which helps us stay focused on our continuous enhancement of the sophomore-level introductory design course. Every element of our course has been incorporated (or discarded) based on the following principles:

1. Teach design with great attention to manufacturing capabilities and limitations.

2. Practice manufacturing and develop manufacturing skills in parallel with the design effort.

3. Teach the design methodology with even emphasis on the theory of design as well as on the practical implementation of the theory.

4. Elevate the students' elementary technical knowledge to a point where they can rely on and develop faith in their elementary engineering analysis skills.

5. Teach and practice organizational and creativity skills such as Brainstorming, Objectives Tree, Reverse Engineering, and Patent Development.

6. Insist on and incorporate the development of oral and written communication skills.

7. Use design teams for the majority of the projects to ensure proper development of interpersonal relationships in a professional setting.

8. Always strive to place realistic constraints on the design projects, these being concerned with material resources and costs, manufacturing resources, production deadlines, performance criteria, intellectual property protection and the element of fair competition.

9. Always be conscious of the effect of the design projects on the safety of the students in the manufacturing environment.

10. Teach this course as a team of professors all of whom are in agreement with and committed to the above principles.

Using these ten points as the 'constitution' of the introductory design course has helped us to ensure that the quality execution of the course remains intact regardless of which team of professors teach it. When more teachers are needed or someone shows an interest in teaching the course, we share these principles with him/her. This allows the professor who is new to the course to get a fast start while we get an opportunity to make improvements to our philosophy based on his/her input.

\section{INNOVATIONS AND IMPLEMENTATION}

Through the years, we have made a few disturbing observations which impelled us to take a closer look at our effectiveness in teaching design. We observed that most designs, even those with good theoretical basis, would commonly fail during the competition. We traced the cause of 
these frequent failures to the lack of sufficient knowledge of manufacturing issues that need to be accommodated during the design stage. This lack of awareness would make many designs fall victim to poor manufacturing practices. The best we could hope was that the students would learn that the design process does not end on a piece of paper. As a matter of fact, the student feedback boasted about how they had learned that carrying a design from paper to a successful prototype is a difficult task! In our view, this negative learning did not constitute an effective value-added educational process.

We also observed that most of the designs were being developed through excessive trial and error during the manufacturing phase. There seemed to be no follow through on the design theory when it came time to manufacture the design. In fact, quite often, we observed that the winning device was designed by the traditional 'seat-of-the-pants' method rather than by employing engineering analysis. Also design tools such as brainstorming, decision tree, failure mode effect analysis, etc. were routinely unused despite the fact that these tools were taught earlier in the course. We traced the cause for these tendencies to the lack of practical knowledge of basic engineering analysis and design tools at the sophomore level.

To correct these rather serious but often overlooked shortcomings, we have implemented several innovative ideas in the sophomore-level "Introduction to Design" course in the last three years. The two most significant enhancements are described below:

\section{Integration of Design and Manufacturing:}

One major change of pedagogical mind-set is the integration of manufacturing with the teaching of design theory. This is done to teach and emphasize the close connection between manufacturing and design by practicing both concurrently. Three years ago, we developed a twotrack system where the students would learn the theory of design process, while simultaneously, they would enhance their manufacturing skills and become aware of our available manufacturing capabilities and limitations. As a result, the students are quite familiar and reasonably skilled with our manufacturing machinery by the time their final design project begins. They have also gained some hands-on experience concerning the importance of considering manufacturing issues while they are engaged in the design process.

There is a machine shop dedicated to this course where all of the manufacturing activities associated with the course occur. This shop is oriented towards working with wooden materials which constitute about $80 \%$ of the materials made available to the students of the introductory design course. We discourage any significant metal work based on the assumption that it would pose considerably higher safety risk to sophomore students.

The shop machinery include several wood lathes, a few milling machines and metal lathes which can be used for both wood and metal work, several drill presses, band saws, sanders, and an assortment of powered hand-tools. Also, each team of students is assigned a tool box containing smaller hand-tools and measurement instruments. They are responsible for the tool box which they keep locked in a locker provided in the machine shop. 


\section{Efficient Development of Engineering Analysis Skills:}

Another major innovation in this course has to do with providing the sophomore students with sufficient theoretical background (beyond Physics and Statics) to enable them to base their designs on as much engineering analysis as possible. To encourage this good design habit, we at first demanded that the student teams submit manufacture-ready engineering drawings before they are allowed to start the manufacturing stage. We soon noticed that lack of sufficient knowledge of basic machine components made our demand rather impractical.

We then searched for a textbook which would teach the design process and some intermediate knowledge of engineering analysis without forgetting that this knowledge would have to be applied before it is fully understood. We were not successful at finding a textbook that shared our vision of teaching design and manufacturing while leaving enough time for hands-on implementation of the concepts in our 11-week term.

We finally developed our own simplified handbook of machine design in which we introduced several machine components with their basic governing equations and principles, but without going into the science behind their theoretical principles. We left that task up to junior- and senior-level Machine Design course. Some of the components included in our handbook are: common mechanisms, DC motors, disk clutches, band brakes, pulleys, belts, gears, cams, and coil springs. As is appropriate for a handbook, these machine components are described from an application (rather than a derivation) point of view. Our design projects are formulated to incorporate most of the machine components covered by the handbook.

Also in the handbook, we have included several design tools, namely brainstorming, decision tree, failure mode effect analysis and efficient reading of patents. These tools are described at a depth sufficient enough for application to our design projects.

\section{DETAILED COURSE DESCRIPTION}

The introductory sophomore design course consists of two parts which are shown in session-bysession detail in Table I representing a typical term. Part one covers the first six weeks of the course and its purpose is to impart the knowledge that is needed to carry out the second part of the course in a meaningful way. This knowledge consists of:

1. development of manufacturing skills and awareness,

2. exposure to sufficient engineering analysis, and

3. familiarization with a few useful design tools.

Part two of the course (bounded by heavy border line in Table I) takes the remaining five weeks and is focused on an open-ended design project which is carried through the typical steps of a design process from problem identification, to conception, to analysis, to manufacturing and finally to documentation and competition. 
Part One: In part one, the theory of design is discussed. At the same time, a rudimentary working knowledge of various machine components is developed with the help of the handbookstyle text prepared for this course. These components include: mechanisms, coil springs, DC motors, clutches, gears, and belt drives. Also, several design tools such as brainstorming, decision tree, and failure mode effect analysis are presented to the students.

\section{Table I: Session-by-Session Planner for a Typical Term}

\begin{tabular}{|c|c|c|c|}
\hline WEEK & SESSION 1 (1 hour) & SESSION 2 (2 hours) & SESSION 3 (2 hours) \\
\hline WK 1 & $\begin{array}{l}\text { 1. Course Introduction } \\
\text { 2. Napkin Assignment }\end{array}$ & $\begin{array}{l}\text { 1. Creativity Project } \\
\text { (How does it work?) } \\
\text { 2. Team Set-up }\end{array}$ & $\begin{array}{l}\text { 1. Model Shop Safety Rules } \\
\text { 2. Model Shop Orientation } \\
\text { 3. Manufacture/Test/Analysis } \\
\text { Project Introduction \& Strategy }\end{array}$ \\
\hline WK 2 & $\begin{array}{c}\text { Lecture } \\
\text { (Linkages \& Mechanisms) }\end{array}$ & $\begin{array}{c}\text { Report Submission \& } \\
\text { Presentation for Creativity } \\
\text { Project }\end{array}$ & $\begin{array}{c}\text { Manufacture/Test/Analysis Project } \\
\text { (Build Session - start) }\end{array}$ \\
\hline WK 3 & $\begin{array}{c}\text { Lecture } \\
\text { (Clutches, Motors, Springs) }\end{array}$ & Reverse Engineering Project & $\begin{array}{c}\text { Manufacture/Test/Analysis Project } \\
\text { (Build Session - continue) }\end{array}$ \\
\hline WK 4 & $\begin{array}{c}\text { Lecture } \\
\text { (Work, Power, Belt Drives) }\end{array}$ & $\begin{array}{l}\text { 1. Report Submission \& } \\
\text { Presentation for Reverse } \\
\text { Engineering Project }\end{array}$ & $\begin{array}{c}\text { Manufacture/Test/Analysis Project } \\
\text { (Build Session - end) }\end{array}$ \\
\hline WK 5 & $\begin{array}{c}\text { Lecture } \\
\text { (Friction Drives, Gears, \& } \\
\text { Brakes) } \\
\end{array}$ & $\begin{array}{c}\text { Manufacture/Test/Analysis } \\
\text { Project } \\
\text { (Analysis and Test Session) } \\
\end{array}$ & $\begin{array}{c}\text { Lecture } \\
\text { (Design Process, Brainstorming, } \\
\text { Concept Tree \& Failure Mode } \\
\text { Effect Analysis) } \\
\end{array}$ \\
\hline WK 6 & $\begin{array}{l}\text { Lecture } \\
\text { (Patents) }\end{array}$ & $\begin{array}{c}\text { 1. Report Submission \& } \\
\text { Presentation } \\
\text { Manufacture/Test/Analysis } \\
\text { Project } \\
\text { 2. Team Re-Assignment }\end{array}$ & $\begin{array}{l}\text { 1. Open-Ended Design Project } \\
\text { Introduction } \\
\text { 2. Identification \& Ideation } \\
\text { (Brainstorming, \& Concept Tree) }\end{array}$ \\
\hline WK 7 & $\begin{array}{c}\text { Ideation \& Feasibility } \\
\text { (Brainstorming, Concept } \\
\text { Tree \& Failure Mode Effect } \\
\text { Analysis ) }\end{array}$ & $\begin{array}{l}\text { 1. Feasibility \& Refinement } \\
\text { 2. Patent Generation }\end{array}$ & $\begin{array}{l}\text { 1. Patent Submission \& } \\
\text { Presentation } \\
\text { 2. Start of Detailed Design }\end{array}$ \\
\hline WK 8 & $\begin{array}{l}\text { Detailed Design - continue } \\
\text { (Question \& Answer } \\
\text { Session) }\end{array}$ & $\begin{array}{l}\text { 1. Detailed Design - continued } \\
\text { (Question \& Answer Session) }\end{array}$ & $\begin{array}{c}\text { Detailed Design Report Submission } \\
\text { \& Approval }\end{array}$ \\
\hline WK 9 & $\begin{array}{l}\text { Start of Prototype } \\
\text { Manufacturing }\end{array}$ & $\begin{array}{l}\text { Prototype Manufacturing } \\
\text { (continue) }\end{array}$ & $\begin{array}{l}\text { Prototype Manufacturing } \\
\text { (continue) }\end{array}$ \\
\hline WK 10 & $\begin{array}{l}\text { Prototype Manufacturing } \\
\text { (continue) }\end{array}$ & $\begin{array}{l}\text { Prototype Manufacturing } \\
\text { (continue) }\end{array}$ & $\begin{array}{l}\text { Prototype Manufacturing } \\
\text { (continue) }\end{array}$ \\
\hline WK 11 & $\begin{array}{l}\text { Prototype Manufacturing } \\
\text { (end) }\end{array}$ & Prototype Certification & Prototype Re-Manufacturing \\
\hline
\end{tabular}

Part one also contains three short-term projects. The first project deals with the concept of design creativity and engineering communication. Here, a commercial electro-mechanical device of reasonable internal complexity (e.g. jar opener, hand-held button stitcher, etc.) is presented to the 
students, They are requested to design the internal mechanism(s) of the device without having the opportunity to look inside the device. They then must present their design concepts via drawings and oral description. The main objective of this exercise is to develop communication skills needed for conveying design ideas.

In the second project, a reverse engineering analysis is performed using the device used for the creativity project. Here, teams of students open up the device with the purpose of recommunicating the actual design of the internals and their critique of its advantages and disadvantages. They are also expected to perform at least one engineering analysis of the device and compare the results to either a measurement they have performed or to the manufacturer's claims if available. For example, they may compute the power capacity of the motor based on their torque measurements and compare that to the motor specifications.

In parallel to these projects, all design teams spend one lab period (two hours) per week on a manufacturing project. Here, they manufacture a device which has been pre-designed by the professors. This project is presented to the teams in the form of engineering drawings (blue prints), and the students must use their own judgment in assessing which dimensions are crucial for the successful operation of the device and which can be changed at will. The device incorporates most of the machine components that are covered by the handbook. Once the device is built, it is operated and measurements are taken. The results must then be compared to the analytical predictions based on the knowledge gained from the handbook. In this manner, not only manufacturing skills have been cultivated, but also the theory of some engineering analyses has been put into practice.

All of the projects carried out in part one conclude in a report and an oral presentation carried out by each team and evaluated by all other class members.

Part Two: The final project starts in the sixth week when the professor submits to the design teams a request for the design and manufacture of a device. The purpose of the final project is to put the knowledge accumulated in part one of the course into practice. Every step of a typical design process is performed and appropriate design tools are used in each step.

One of our recent projects required the design and manufacture of a device that would "walk" a distance of four feet and then return to its starting point unassisted without violating the course boundaries which were 30 inches apart.

Since we believe that at the heart of effective teaching of engineering design there must be attention to realistic constrains, we have incorporated the following constraints in the introductory sophomore design course:

1. Material Resources: the student teams are given a list of materials to which they are strictly limited. Most of these materials are wooden (boards, craft sticks, dowel rods, etc.). In order to keep the safety level high for the sophomores, very few metallic materials are allowed (nails, screws, small piece of sheet metal, etc.). Also, in order to encourage creativity, very few premanufactured components are allowed (DC motor, coil springs, and bearings). 
2. Cost of Material: Every piece of material that the student teams use has a cost point associated with it. Designs which result in high material cost will receive penalty points in the competition. Bartering of partially used materials amongst the teams is an acceptable practice.

3. Manufacturing Resources: The student design teams are not allowed to use any manufacturing tools outside of what is available in our model shop. Through the use of the equipment in the early projects of the course, the student teams become closely familiar with their manufacturing capabilities and limitations by the time they start the final project.

4. Production Deadlines: The design and manufacturing process is broken into compartments of time which are strictly enforced. For example, if a student team takes too long in the design stage (usually due to sloppy time management), they will lose valuable manufacturing time. Also, the manufacturing time is limited hence encouraging team work and task delegation.

5. Performance Criteria: Every project has a well-defined mathematical performance criteria which usually includes the trade-off effects of cost, weight, speed and efficiency.

6. Team Work: Every aspect of the project is carried out in teams of three (and rarely four) students. Task delegation is left up to the teams. Conflicts are encouraged to be resolved rather than ignored. At the end, confidential rating of each team member's participation is submitted by all students. The team grade is modified for each student according to these ratings.

7. Patent Protection: Each team submits a simplified patent composed of a few claims and sufficient description in order to protect their conceptual design ideas form being copied. All patents are reviewed by all involved professors and claims are approved or rejected. A master copy of all of the submitted patents are made available to all design teams. Patent infringement claims are presented to the board of professors by the involved teams. The board's decision is final, however, settlement of the dispute prior to the announcement of the decision is highly encouraged.

8. Competition: All designs are subject to a qualification test and a final course-wide (all sections) competition. The outcome of the competition has absolutely no direct effect on the students course grade. Instead, a major portion of their grades is based on a final report which is to fully document their design stages and their diagnosis of what went wrong and what performed as intended during the competition. The winners, however, are appropriately rewarded by a prize such as a commercially available engineering handbook.

\section{IMPACT OF INNOVATIONS}

The principle components of the two innovations described here have been implemented into the sophomore-level "Introduction to Design" course for approximately three years. During this period, however, several enhancements have been made at the smaller detail level. Four faculty members (the authors) have been responsible for teaching and continuous improvement of the 
course, while approximately 900 students have been exposed to these innovations in the last three years.

The two-track teaching system explained in this article, combined with our quarter-style terms (11 weeks + finals), has created the added burden of requiring a model shop technician responsible for continuous up-keep of material supply, machinery and tooling in the model shop. At the same time, meaningful implementation of our strategy has necessitated a moderate but continuous amount of financial support, which we have been fortunate to secure in the form of industrial endowment funds and machine component donations.

The impact of the innovations is quite obviously demonstrated by the much-improved performance of the manufactured designs. Currently, we typically achieve a 50 to $75 \%$ success rate in our course-wide final competitions as opposed to 25 to $50 \%$ in the past. This increase in the rate of success has been accomplished despite the increased difficulty level of the competitions. Since most of failures in the past were due to lack of manufacturing insight, we believe that the two-track system is mainly responsible for the increased success rate.

The student feedback has been quite appreciative of the rare opportunity provided by this course to experience a "real" practice of engineering knowledge at an early stage of their undergraduate career.

\section{LESSONS LEARNED}

We have learned that a group of professors can bring more creativity into a design course than any one of them on his/her own. However, the integrity of the course greatly depends on the cooperation of the participating faculty members. To ensure this, we developed the previously mentioned list of ten basic principles which act as the "constitution" of this course. When more teachers are needed or someone shows an interest in teaching the course, we share these principles with him/her. This allows the new teacher to get a fast start while we get an opportunity to make improvements to our philosophy based on his/her suggestions.

We have also learned that as common sense as the design process seems to be, most students (and indeed most professional engineers) have great resistance to practicing it methodically. Therefore, we have to constantly re-focus our students on the process and the tools of engineering design. We have to continuously re-enforce the idea that proper implementation of design process requires discipline and order rather than chaos which is often mistaken for freespirited creativity. 